Marquette University

e-Publications@Marquette

Biomedical Sciences Faculty Research and

Publications

Biomedical Sciences, Department of

$11-2017$

\title{
Corticosterone Regulates Both Naturally Occurring and \\ Cocaine-Induced Dopamine Signaling by Selectively Decreasing Dopamine Uptake
}

\author{
Daniel S. Wheeler \\ Marquette University, daniel.wheeler@marquette.edu \\ Amanda L. Ebben \\ Marquette University \\ Beliz Kurtoglu \\ Marquette University \\ Marissa E. Lovell \\ Marquette University \\ Austin T. Bohn \\ Marquette University
}

See next page for additional authors

Follow this and additional works at: https://epublications.marquette.edu/biomedsci_fac

Part of the Neurosciences Commons

\section{Recommended Citation}

Wheeler, Daniel S.; Ebben, Amanda L.; Kurtoglu, Beliz; Lovell, Marissa E.; Bohn, Austin T.; Jasek, Isabella A.; Baker, David A.; Mantsch, John R.; Gasser, Paul J.; and Wheeler, Robert A., "Corticosterone Regulates Both Naturally Occurring and Cocaine-Induced Dopamine Signaling by Selectively Decreasing Dopamine Uptake" (2017). Biomedical Sciences Faculty Research and Publications. 177.

https://epublications.marquette.edu/biomedsci_fac/177 


\section{Authors}

Daniel S. Wheeler, Amanda L. Ebben, Beliz Kurtoglu, Marissa E. Lovell, Austin T. Bohn, Isabella A. Jasek, David A. Baker, John R. Mantsch, Paul J. Gasser, and Robert A. Wheeler 
Marquette University

e-Publications@Marquette

\section{Biomedical Science Faculty Research and Publications/College of Health Sciences}

This paper is NOT THE PUBLISHED VERSION; but the author's final, peer-reviewed manuscript. The published version may be accessed by following the link in th citation below.

European Journal of Neuroscience, Vol. 46, No. 10 (November 2017): 2638-2646. DOI. This article is (C) Wiley and permission has been granted for this version to appear in e-Publications@Marquette. Wiley does not grant permission for this article to be further copied/distributed or hosted elsewhere without the express permission from Wiley.

\section{Corticosterone Regulates Both Naturally Occurring and Cocaine-Induced Dopamine Signaling by Selectively Decreasing Dopamine Uptake}

Daniel S. Wheeler

Department of Biomedical Sciences, Marquette University, Milwaukee, WI Amanda L. Ebben

Department of Biomedical Sciences, Marquette University, Milwaukee, WI Beliz Kurtoglu

Department of Biomedical Sciences, Marquette University, Milwaukee, WI Marissa E. Lovell Department of Biomedical Sciences, Marquette University, Milwaukee, WI Austin T. Bohn Department of Biomedical Sciences, Marquette University, Milwaukee, WI 
Isabella A. Jasek

Department of Biomedical Sciences, Marquette University, Milwaukee, WI

David A. Baker

Department of Biomedical Sciences, Marquette University, Milwaukee, WI

John R. Mantsch

Department of Biomedical Sciences, Marquette University, Milwaukee, WI

Paul J. Gasser

Department of Biomedical Sciences, Marquette University, Milwaukee, WI

Robert A. Wheeler

Department of Biomedical Sciences, Marquette University, Milwaukee, WI

\begin{abstract}
Stressful and aversive events promote maladaptive reward-seeking behaviors such as drug addiction by acting, in part, on the mesolimbic dopamine system. Using animal models, data from our laboratory and others show that stress and cocaine can interact to produce a synergistic effect on reward circuitry. This effect is also observed when the stress hormone corticosterone is administered directly into the nucleus accumbens (NAc), indicating that glucocorticoids act locally in dopamine terminal regions to enhance cocaine's effects on dopamine signaling. However, prior studies in behaving animals have not provided mechanistic insight. Using fast-scan cyclic voltammetry, we examined the effect of systemic corticosterone on spontaneous dopamine release events (transients) in the NAc core and shell in behaving rats. A physiologically relevant systemic injection of corticosterone ( $2 \mathrm{mg} / \mathrm{kg}$ i.p.) induced an increase in dopamine transient amplitude and duration (both voltammetric measures sensitive to decreases in dopamine clearance), but had no effect on the frequency of transient release events. This effect was compounded by cocaine $(2.5 \mathrm{mg} / \mathrm{kg}$ i.p.). However, a second experiment indicated that the same injection of corticosterone had no detectable effect on the dopaminergic encoding of a palatable natural reward (saccharin). Taken together, these results suggest that corticosterone interferes with naturally occurring dopamine uptake locally, and this effect is a critical determinant of dopamine concentration specifically in situations in which the dopamine transporter is pharmacologically blocked by cocaine.
\end{abstract}

We examined the effect of corticosterone on spontaneous dopamine release events (transients) in the NAc core and shell in behaving rats. Corticosterone increased dopamine transient amplitude and duration (measures sensitive to decreases in dopamine clearance), but had no effect on the frequency of transient release events. This effect was compounded by cocaine. These results suggest that corticosterone acts synergistically with cocaine to interfere with naturally occurring dopamine uptake.

\title{
Keywords
}

cocaine; corticosterone; dopamine; stress; voltammetry

People vulnerable to bouts of drug abuse or overeating report that stressful life events can precipitate these maladaptive behaviors (Hyman et al., [ 26] ; Dallman, [ 13] ). Preclinical studies model this impact of stress, showing that noxious stimulation, and the glucocorticoid response that it engenders, can enhance acquisition, escalation, and reinstatement of drug seeking (see Mantsch et al., [ 33] for review). The glucocorticoid hormone corticosterone is required for the acute psychomotor stimulant effects of cocaine (Marinelli et al., [ 34] ,[ 35] ); facilitates the acquisition of cocaine self-administration (Goeders \& Guerin, [ 19] ,[ 20] ); and is required for the 
escalation of cocaine intake under conditions of extended access to the drug (Mantsch \& Katz, [ 32] ). Stressinduced reinstatement of extinguished drug-seeking behavior requires corticosterone (Erb et al., [ 16] ; Mantsch \& Goeders, [ 31] ), although elevations in the hormone alone may not be sufficient to cause reinstatement (Lee et al., [ 28] ; Graf et al., [ 21] ; but see Deroche et al., [15] ). Previous studies indicate that the impact of stress on drug-seeking behavior is, in part, due to the effects of corticosterone on dopamine (DA) signaling in rewardprocessing circuitry. Specifically, corticosterone augments cocaine's ability to increase DA concentration in the nucleus accumbens (NAc), potentiating cocaine-induced locomotor activity and cocaine-induced reinstatement of drug seeking (Rouge-Pont et al., [ 43] ; Graf et al., [ 21] ). In our studies, corticosterone potentiated cocaineprimed reinstatement both when the steroid was administered systemically and when it was directly infused into the NAc, demonstrating that corticosterone acts locally in the NAc to modulate drug seeking behavior (Graf et al., [ 21] ).

In addition to its effects on cocaine seeking, stress also influences the processing of natural rewards, potentially through similar physiological pathways (Reynolds \& Berridge, [ 41] ; Volkow et al., [ 54] ; Berridge, [ 4] ). Stress can cause overeating, particularly of palatable foods, in both laboratory animals and overweight people (Rowland \& Antelman, [ 44] ; Dallman, [ 13] ). As with cocaine, behavioral and dopaminergic responses to natural rewards are modulated by glucocorticoids. Adrenalectomized rats exhibit reduced consumption of natural gustatory rewards, and regular levels of consumption are restored by corticosterone supplement (Bell et al., [ 3 ] ; Bhatnagar et al., [ 6 ] ). Furthermore, exogenous glucocorticoid administration causes overeating and weight gain (Tataranni et al., [ [0] ). The influence of corticosterone on natural reward processing likely cooccurs with an increase in DA levels in the NAc in response to palatable foods. Corticosterone facilitates DA signaling in the NAc (Barrot et al., [ 2] ), and rats will readily self-administer corticosterone itself, the consumption of which increases DA, particularly during feeding (Piazza et al., [ 39] ).

The notion that stress and glucocorticoids may contribute to both obesity and addiction through a common dopaminergic mechanism is intriguing (Volkow et al., [ 54] ). Using fast-scan cyclic voltammetry in behaving rats, we examined the effects of corticosterone on subsecond DA signaling in the NAc to determine: (i) the specific components of spontaneous DA signals altered by corticosterone alone, (ii) the effects of corticosterone on DA signaling after cocaine administration, and (iii) the effects of corticosterone on DA signals in response to a natural reward. Scrutinizing individual characteristics of spontaneous dopamine release events (i.e. transients) can reveal a selective influence on extracellular DA signaling, and potentially suggest corticosterone's mechanism of action. The frequency of observed transients reflects DA release frequency, a factor that is dictated by the burst firing of DA neurons. Peak transient amplitude is sensitive to factors that influence both release and clearance, and transient duration (as measured by half-width) is affected by changes in DA clearance (Wightman et al., [ 58] ; Cragg \& Rice, [ 12] ; Aragona et al., [ 1 1] ). For example, several reinforcing drugs (e.g. nicotine, ethanol, and cocaine) increase dopamine concentration, but of these, only cocaine increases transient duration, indicative of its actions blocking the dopamine transporter (Cheer et al., [ $\underline{8}$ ] ). The following findings indicate that corticosterone preferentially affects DA uptake and is more influential in situations in which the DA transporter is blocked by cocaine.

\section{Methods}

\section{Subjects}

Male Sprague-Dawley rats (Envigo) weighing 275-300 g were individually housed in a temperature and humidity controlled AAALAC-accredited vivarium. Rats were maintained on a 12/12 reversed dark/light cycle, and all experimental procedures were conducted during the dark phase (starting at 0700 hours) to more closely approximate the procedures of Graf et al. ([ 21] ] ). All experimental protocols were approved by the Institutional Animal Care and Use Committee at Marquette University in accordance with the National Institutes of Health 
Guide for the Care and Use of Laboratory Animals. Seventeen (10 corticosterone and seven vehicle treated) rats were used in the cocaine experiment, and five naïve rats were used in the saccharin experiment.

\section{Surgical procedures}

All surgical procedures were conducted under ketamine/xylazine (100 mg/kg; $20 \mathrm{mg} / \mathrm{kg}$, i.p.) anesthesia. A 1-mm diameter electrode guide cannula (BASi) was implanted above the NAc core (AP: +1.3 ; ML: \pm 1.3 ) or NAc shell (AP: +1.7; $\mathrm{ML}: \pm 0.8$ ) unilaterally, and a $\mathrm{Ag} / \mathrm{AgCl}$ reference electrode was placed contralateral to the guide cannula. For the saccharin experiment, a single intraoral catheter was implanted as previously described (Wheeler et al., [ 55] ). For all surgical procedures, rats were treated with the anti-inflammatory meloxicam (1\% oral suspension) the day of, and for 4 days following surgery to reduce inflammation and postoperative pain.

\section{Apparatus}

Both experiments were conducted in a standard operant chamber (Med Associates), interfaced with a computer, and housed in sound attenuating Faraday cages. The operant chamber had a dedicated syringe pump for intraoral infusions of saccharin sodium salt $(0.15 \%$ based on the weight of the salt; Sigma) that were delivered to each rat via a single-channel fluid swivel (Instech Laboratories). The chamber floor was clear acrylic glass, and illumination was provided by a house light positioned on the door of the sound-attenuating chamber. Rats were harnessed to a rotating commutator (Crist Instruments) for electrochemical recordings. Corticosterone ( $1 \mathrm{mg} / \mathrm{mL}$; Sigma) was dissolved in a $90 \%$ saline and $10 \%$ ethanol vehicle solution (Spencer \& Deak, [ 48] ). Cocaine $\mathrm{HCl}$ (NIDA; $8.25 \mathrm{mg} / \mathrm{mL}$ based on the weight of the salt) was dissolved in a saline vehicle.

\section{Cocaine experiment}

On a day prior to DA measurements, subjects were habituated to the recording environment for approximately $1 \mathrm{~h}$. The experiment consisted of DA measurements during a 30-min baseline phase, a 40-min corticosterone or vehicle phase, and a 40-min cocaine phase (see Fig. [ $\mathrm{NaN}]$ ). Corticosterone ( $2.0 \mathrm{mg} / \mathrm{kg}$ i.p.) and cocaine $(2.5 \mathrm{mg} / \mathrm{kg}$ i.p.) were administered immediately before their respective recording phases. This dose of corticosterone produces a plasma corticosterone level similar to that produced by an acute stressor (Graf et al., [21] ). The low dose of cocaine was specifically chosen because it does not produce reinstatement of cocaine seeking when administered alone, but does cause reinstatement when administered with corticosterone (Graf et al., [ 21] ). Before each experiment, a carbon fiber electrode was lowered into the NAc. The fiber was held at $-0.4 \mathrm{~V}$ between scans and then driven to $+1.3 \mathrm{~V}$ and back in a triangular fashion at $400 \mathrm{~V} / \mathrm{s}$ for each voltammetric measurement. The application of this triangle waveform causes oxidation and reduction in chemical species that are electroactive within this potential range, producing a change in current at the carbonfiber. Specific analytes (including $\mathrm{DA}$ and $\mathrm{pH}$ ) are identified by plotting these changes in current against the applied potential to produce a cyclic voltammogram (Heien et al., [ 22] , [ 23] ). The current arising from electrode processes was removed using background subtraction. Recordings were blocked into 30-s bins, and the background period was taken as the nadir during each bin. This practice does not subtract the presence of spontaneous DA release events because the background was explicitly selected for the absence of DA signals. Measurements were made every 100 ms and, after driving the electrode into the NAc, the electrode equilibrated for 40 min before any data were collected. Because the present experiment required an analysis of naturally occurring DA signaling, the dorsoventral position of the microelectrode was optimized by monitoring the presence of spontaneously occurring DA release events (Wightman et al., [ 59] ; Roitman et al., [ 42] ; Wheeler et al., [ $\underline{56}$; Twining et al., [ 51] ). Once this was observed, the electrode was locked in place and data collection proceeded.

Analyte identification and quantification were achieved using a principal component regression analysis described in detail elsewhere (Heien et al., [ 22] ). All data presented here fit the resulting model at the 95\% confidence level. Briefly, training sets were generated from background-subtracted cyclic voltammograms 
collected during and after electrical stimulations. DA was isolated with a chemometric analysis using a previously recorded training set (Twining et al., [ 51] ; Wheeler et al., [ 57] ) matched for oxidation potential and transient amplitude. The resulting current amplitude was converted to DA concentration based on the average postexperiment electrode sensitivity (Wheeler et al., [ [5] ). Transient analysis was adapted from Vander Weele et al. ([ $\underline{53}]$ ). Transients were identified with MATLAB (code provided by Dr. Richard Keithley) and characterized with Mini Analysis (Synaptosoft). Transients were defined as DA fluctuations that exceeded $20 \mathrm{~nm}$, lasted at least $200 \mathrm{~ms}$, and were at least five times greater than the root-mean-square noise sampled during a 2-s period in each trial.

\section{Saccharin experiment}

Because the DA response to saccharin is variable between subjects and brief relative to the effects of cocaine, a purely within-subjects design was employed to maximize sensitivity to any potential effect of corticosterone. Furthermore, all recordings were made in the NAc shell because DA signaling in this subregion is more sensitive to primary rewarding or aversive stimuli (Wheeler et al., [ [6] ] ). On a day prior to DA measurements, subjects were habituated to the recording environment for approximately $1 \mathrm{~h}$. During the habituation session, all subjects received 30 intraoral infusions of a $0.15 \%$ saccharin solution $(0.2 \mathrm{~mL}$ over $15 \mathrm{~s})$ to reduce any neophobia during the experiment. The experiment consisted of DA measurements during a 30-min pre-corticosterone saccharin phase, a 40-min corticosterone phase, and a 30-min post-corticosterone saccharin phase (see Fig. [NaN] A). Subjects received 30 intraoral infusions during each saccharin phase. DA measurements were acquired and isolated as in the cocaine experiment. In order to assess the phasic response to saccharin before and after corticosterone administration, each trial was divided into a 10-s pre-infusion baseline epoch and a 20-s infusion epoch. Background was subtracted from the nadir during the baseline epoch. After conducting chemometric analyses, the average DA concentrations during the two epochs were compared.

\section{Histology}

After the completion of each experiment, subjects were euthanized with $\mathrm{CO}_{2}$ according to Institutional Animal Care and Use Committee guidelines. To verify placements of voltammetry recordings, small electrolytic lesions were created by running a current $(250 \mu \mathrm{A})$ through a stainless steel electrode placed the depth at which the recording took place. Brains were then removed and submerged in $10 \%$ formaldehyde for 14 days. All brains were then sliced into $40-\mu \mathrm{m}$ sections, mounted, stained with $0.25 \%$ thionin, and coverslipped.

\section{Statistical analysis}

In the cocaine experiment, time-averaged DA concentrations, transient frequency, half-width, and amplitude were analyzed with four separate 2 (group: corticosterone vs. vehicle) $\times 3$ (phase: baseline vs. treatment vs. cocaine) mixed anovas followed by planned contrasts to determine whether DA is elevated during the treatment phase (relative to baseline) and again during the cocaine phase (relative to the treatment phase). In the saccharin experiment, time-averaged DA concentrations were analyzed with a 2 (epoch: baseline vs. infusion) $\times$ 2 (phase: pre- vs. post-corticosterone) within-subjects anova. Statistical analyses were performed using Statistica 6.0 (Stat Soft).

\section{Results}

\section{Corticosterone and cocaine interacted to increase extracellular DA in the NAc}

In the first experiment, potential interactions between cocaine and corticosterone in the regulation of overall DA concentration were assessed in the NAc core and shell. Figure [ $\mathrm{NaN}]$ depicts the experimental design and time-averaged DA concentration (average color plots) from representative corticosterone- and vehicle-treated rats across the three experimental phases. A comparison of core $(n=4)$ and shell $(n=6)$ electrode placements in corticosterone-treated rats showed an effect of phase, $F_{2,16}=23.54, P<0.001$, but no effect of placement, 
$F_{1,8}=0.44, P=0.53$, and no placement $\times$ phase interaction, $F_{2,16}=0.98, P=0.40$ (see Fig. $[\mathrm{NaN}] \mathrm{A}$ ). Therefore, core and shell data were collapsed in subsequent analyses. Corticosterone appeared to cause an elevation in average DA concentration, and only corticosterone-treated rats exhibited an increase in DA concentration after the injection of cocaine (see Fig. [NaN] B). anova revealed an effect of phase, $F_{2,30}=13.92, P<0.001$, and a group $\times$ phase interaction, $F_{2,30}=12.62, P<0.001$, but no effect of group, $F_{1,15}=1.15, P=0.30$. Planned contrasts showed that corticosterone elevated DA above baseline levels, $F_{1,15}=9.95, P<0.007$, and cocaine further elevated DA above the level observed with corticosterone alone, $F_{1,15}=33.82, P<0.001$. Vehicle injections produced no elevation of DA above baseline, $F_{1,15}=3.03, P=0.10$, and cocaine alone produced no elevation relative to the vehicle phase, $F_{1,15}=0.91, P=0.36$. Although the latter null result may seem counterintuitive, the low dose of cocaine administered here does not facilitate reinstatement of cocaine seeking and does not increase DA as measured by microdialysis (Graf et al., [ 21] ). Figure [NaN] C depicts electrode placements for the corticosterone and vehicle groups.

\section{Corticosterone selectively affected measures of DA uptake}

Next, the characteristics of spontaneous DA transient release events were scrutinized to determine whether corticosterone preferentially affected release or uptake. Figure $[\mathrm{NaN}] \mathrm{A}$ depicts the measured characteristics of transient DA release events. Transient frequency is primarily an indicator of DA release, transient amplitude is affected by both release and uptake, and half-width is primarily influenced by uptake (Cragg \& Rice, [ 12] ; Aragona et al., [ 1] ; Vander Weele et al., [ 53] ). anovas were conducted to examine each characteristic. An analysis of transient amplitude revealed an effect of phase, $\mathrm{F}_{2,30}=8.94, \mathrm{P}<0.001$, and a group $\times$ phase interaction, $F_{2,30}=5.80, P<0.008$, but no effect of group, $F_{1,15}=2.43, P=0.14$ (see Fig. [NaN] B). Similar to the pattern observed in the time-averaged concentration data, transient amplitude was augmented by corticosterone, $F_{1,15}=9.86, P<0.007$, and further elevated by cocaine, $F_{1,15}=11.51, P<0.005$. No similar effects were observed in the vehicle condition, $\mathrm{Fs}<3.6$, Ps $>0.07$. The analysis of transient half-width showed an effect of phase, $F_{2,30}=51.34, P<0.001$, and a group $x$ phase interaction, $F_{2,30}=21.37, P<0.001$, but no effect of group, $F_{1,15}=4.33, P>0.054$ (see Fig. $[\mathrm{NaN}] \mathrm{C}$ ). As with time-averaged concentration and transient amplitude, transient half-width was increased by corticosterone, $F_{1,15}=24.75, P<0.001$, and further increased by cocaine $F_{1,15}=68.39, P<0.001$. Vehicle produced no effect, $F_{1,15}=0.41, P=0.53$, but cocaine did have an effect on halfwidth after vehicle injection, $F_{1,15}=6.36, P<0.03$. This increase in half-width seems to be relatively weak, as it is not reflected in the time-average DA concentration measurement. However, the corticosterone group exhibited longer transients than the vehicle group during the cocaine phase, $F_{1,15}=17.72, P<0.001$, showing that corticosterone potentiated the effect that cocaine normally has on half-width. In contrast, the frequency of transient release events was unaffected by corticosterone, vehicle, or cocaine, Fs $<2.68$, Ps $>0.08$ (see Fig. [NaN] D), suggesting that DA neuron activity was not generally excited by administration of either corticosterone or cocaine. Thus, corticosterone and cocaine selectively inflated measures that are sensitive to reductions in DA clearance, but had no appreciable effect on the number of release events.

\section{Corticosterone did not affect the DA response to gustatory rewards}

Finally, because corticosterone alone had an effect on DA signaling, and because past microdialysis studies have indicated that exogenous corticosterone increases DA levels in the NAc particularly during feeding (Piazza et al., [39] ), we examined the possibility that the steroid would modulate the DA response to saccharin, an appetitive natural reward. Figure [NaN] A shows the timing of events for each rat in the saccharin experiment. An intraoral saccharin infusion normally produces a phasic DA release in the NAc shell (see Fig. [NaN] B; Roitman et al., [ $\underline{42}$ ] ; Wheeler et al., [ 56] , [ 57] ). Here, naturally rewarding saccharin produced a phasic increase in DA that was unaffected by corticosterone administration (Fig. [NaN] $\mathrm{C}$ and D). anova revealed an effect of epoch, $\mathrm{F}_{1,4}=14.84$, $P<0.02$, but no other effect or interaction, $\mathrm{Fs}<0.10$, $\mathrm{Ps}>0.77$. Figure $[\mathrm{NaN}] \mathrm{E}$ depicts the electrode placements in the NAc shell. 


\section{Discussion}

Microdialysis studies have demonstrated that stress and glucocorticoids can increase DA in the NAc and augment the effect of cocaine on DA concentration, but mechanistic insight into how this occurs has been lacking (Piazza et al., [ 39] ; Graf et al., [ 21] ). Using fast-scan cyclic voltammetry in behaving rats, we found that a physiologically relevant injection of corticosterone selectively increases the amplitude and duration of spontaneous DA release events, and markedly augments cocaine's effect on those measures. These observations provide unique insight into the mechanisms by which corticosterone and cocaine interact to influence DA signaling during moment-to-moment behavior.

\section{The effect of corticosterone on spontaneous DA signaling}

There are at least two mechanisms by which corticosterone might enhance DA signaling in the NAc. First, corticosterone can act in the ventral tegmental area (VTA) to increase the sensitivity of VTA neurons to glutamatergic signaling. Specifically, corticosterone has been shown to lower NMDA excitatory thresholds in the VTA (Berry et al., [ 5$]$ ), and to augment spontaneous neural firing in the presence of AMPA or NMDA through a non-genomic mechanism under temporal parameters similar to those used in the present studies (Cho \& Little, [ 10] ). However, it is unlikely that an increase in glutamate sensitivity in DA neurons would selectively affect transient amplitude and duration, but not frequency. In fact, NMDA in the VTA induces burst firing in DA neurons (Chergui et al., [9] ), and NMDA receptor antagonism explicitly reduces transient frequency in the NAc (Sombers et al., [ 46] ). Thus, although there may be situations in which corticosterone can alter glutamate sensitivity in VTA neurons, it is unlikely that changes in DA neuron sensitivity to glutamate are responsible for the results observed here.

Instead, the pattern of results suggests that corticosterone is acting locally in the NAc to interfere with DA uptake mechanisms. We have previously demonstrated that corticosterone can potentiate cocaine-primed reinstatement of drug seeking even when infused directly into the NAc, supporting the hypothesis that it acts locally in DA terminal regions to potentiate the effects of cocaine on DA (Graf et al., [ 21] ). One likely mechanism of action is corticosterone's blockade of uptake 2 -mediated DA clearance in the NAc (Iversen \& Salt, [ 27] ). Recent studies specifically implicate organic cation transporter 3 (ОCT3), an uptake ${ }_{2}$ transporter inhibited by corticosterone at physiological concentrations (Gasser et al., [17] ; Hill et al., [ 24] ), in the ability of stress and corticosterone to potentiate cocaine-primed reinstatement. These studies demonstrate: (i) that corticosterone decreases DA transporter-independent DA clearance in the NAc of anesthetized rats; and (ii) that mice genetically engineered to lack OCT3-mediated transport (Wultsch et al., [ 60] ) do not exhibit the corticosteroneinduced potentiation of cocaine-primed reinstatement that is observed in wild-type mice (McReynolds et al., [ 37] ). Considering this convergent evidence, it is likely that the effects of corticosterone on DA transients observed in the current studies are due to local actions of the hormone in the NAc to block OCT3-mediated DA clearance, resulting in prolonged DA transients that are further lengthened by cocaine's actions on the DA transporter.

\section{The effect of corticosterone and cocaine on spontaneous DA signaling}

This is the first description of an interaction between corticosterone and cocaine in the regulation of subsecond DA signaling in awake and behaving animals. Previous studies have reported that cocaine alone boosts transient frequency, amplitude, and duration, particularly in the shell of the NAc (Stuber et al., [ 49] ; Aragona et al., [ 1 ] ). Aragona et al. ([ 1$]$ ) found that cocaine increased transient amplitude and half-width equally in the core and shell regions, but preferentially increased transient frequency in the shell subregion. This core/shell difference could be facilitated by corticosterone, as microdialysis experiments have shown that cocaine-induced DA concentration increases in the shell, but not the core, require endogenous corticosterone (Barrot et al., [ 2] ). In contrast, we found that a comparatively low dose of cocaine, when combined with corticosterone, increased 
transient amplitude and half-width in the core and shell regions, but did not affect frequency in either region. As stated above, this suggests that the low dose of cocaine, combined with corticosterone, is not likely acting in the VTA to increase DA neuron burst firing rates, but instead selectively regulating DA clearance. Based on the previous findings, a larger dose of cocaine would almost certainly preferentially boost DA in the shell and increase transient frequency either through a pre-synaptic mechanism or through disinhibitory NAc feedback to the VTA (Aragona et al., [ 1] ; Bocklisch et al., [ 7] ). Perhaps not coincidentally, sensitivity to the rewarding effects of cocaine at higher doses is less affected by stress or the administration of exogenous corticosterone (Goeders \& Guerin, [ 18] ; Mantsch \& Goeders, [ $\underline{30}]$ ).

\section{The effect of corticosterone on saccharin-induced DA release}

Although corticosterone had a clear synergistic relationship with cocaine, it had no effect on the DA response to the natural gustatory reward, saccharin. This indicates that corticosterone can differentially affect the processing of natural and drug rewards. This finding is somewhat surprising because stress and glucocorticoids can increase the consumption of palatable foods (Rowland \& Antelman, [ 44] ; Dallman et al., [ 14] ; Dallman, [13] ), and previous studies have found that corticosterone facilitates consumption of and appetitive responses to saccharin (Silva, [ 45] ; Bhatnagar et al., [ 6] ), which presumably would be reflected in DA signaling. However, there are factors to consider that may explain why corticosterone selectively affected the DA response to cocaine. In studies describing a reduction of saccharin consumption or palatability in adrenalectomized rats, there is no evidence of enhanced saccharin consumption or palatability in situations in which corticosterone is elevated above normal levels. That is, there may be a certain level of circulating corticosterone that is required for normal saccharin palatability, but elevations beyond that threshold do not augment palatability. Additionally, we are not aware of studies demonstrating that acute stress or glucocorticoid administration enhance the palatability or consumption of saccharin in intact rats, and they may even decrease motivation to consume saccharin (Plaznik et al., [ 40] ; Howell et al., [ 25] ). It is likely that DA signaling would be dramatically altered in animals with low corticosterone levels, as DA flexibly tracks reward value (Wheeler et al., [56] , [ 57] ; McCutcheon et al., [ 36] ; Cone et al., [ 11] ), but it is unaffected in healthy animals in which corticosterone can fluctuate naturally.

Finally, it is important to note that stress and glucocorticoids could potentiate DA responses to natural rewards under different conditions. Many studies that observe an increase in eating due to stress or glucocorticoids involve repeated exposures to stress, stress hormones, and calorically dense food (Dallman et al., [ 14] ; Dallman, [ 13] ; Sominsky \& Spencer, [ 47] ). This sort of experience could produce changes in how stress and food stimuli interact neurologically based on homeostatic pressures or learned compensatory or prophylactic behaviors (Pecoraro et al., [ 38] ; Ulrich-Lai et al., [ 52] ; Liang et al., [ 29] ). In the present study, the exposure to corticosterone was acute, saccharin is palatable but non-caloric, and there was no opportunity for subjects to learn any association between food consumption and the stress response. In other situations, glucocorticoids can stimulate appetite through many physiological pathways (Sominsky \& Spencer, [ 47] ), but the present results suggest that the critical appetite-inducing action of corticosterone is not likely to be a selective reduction of DA clearance in the NAc.

\section{Conclusion}

Stress and the cascade of physiological events that it induces have a profound effect on motivated behavior. This leaves open the possibility that stress-induced glucocorticoid release influences DA responses to drugs of abuse and natural rewards via a common pathway. Here, we observed that one potential mechanism, corticosterone's impact on DA clearance, boosts the increase in extracellular DA caused by cocaine, but does not affect the DA response to a natural reward. The results reveal a corticosterone-sensitive DA clearance mechanism that, in 
concert with the DA transporter, contributes to the regulation of dopaminergic neurotransmission in the NAC and may underlie stress and glucocorticoid influences on cocaine-seeking behavior.

\section{Acknowledgements}

NIDA Grants DA-032895 (PJG) and DA-025679 (RAW) provided support for this research. We would like to thank Caitlin J. Vander Weele for transient analysis consultation, Richard B. Keithley for the MATLAB transient detection program, and Chung-Lung Chan for comments on the manuscript.

\section{Conflict of interest}

The authors declare no conflicts of interest.

\section{Author contributions}

D.A.B., J.R.M., P.J.G., and R.A.W. conceived the study and designed the methodology. D.S.W., A.L.E., B.K., M.E.L., A.T.B., and I.A.J. performed the experiments. D.S.W., A.L.E., and M.E.L. performed the analyses of the experimental data. D.S.W. wrote the article with contributions and input from R.A.W. and P.J.G.

\section{Data accessibility}

Research data pertaining to this article is located at figshare.com: https://0-doi-

org.libus.csd.mu.edu/10.6084/m9.figshare.5417353.v1.

Abbreviations

DA dopamine

NAc nucleus accumbens

OCT3 organic cation transporter 3

VTA ventral tegmental area

\section{Footnotes}

1 Edited by Michel Barrot

$\underline{2}$ Reviewed by Shelly Flagel, University of Michigan, USA; Catherine Le Moine, University of Bordeaux, France $\underline{3}$ The associated peer review process communications can be found in the online version of this article. $\underline{4}$ Laboratory of Origin: Wheeler and Gasser labs

$\underline{5}$ These authors contributed equally.

\section{References}

Aragona, B.J., Cleaveland, N.A., Stuber, G.D., Day, J.J., Carelli, R.M. \& Wightman, R.M. ( 2008 ) Preferential enhancement of dopamine transmission within the nucleus accumbens shell by cocaine is attributable to a direct increase in phasic dopamine release events. J. Neurosci., 28, $8821-8831$.

Barrot, M., Marinelli, M., Abrous, D.N., Rouge-Pont, F., Le Moal, M. \& Piazza, P.V. ( 2000 ) The dopaminergic hyper-responsiveness of the shell of the nucleus accumbens is hormone-dependent. Eur. J. Neurosci., $12,973-979$.

Bell, M.E., Bhatnagar, S., Liang, J., Soriano, L., Nagy, T.R. \& Dallman, M.F. ( 2000 ) Voluntary sucrose ingestion, like corticosterone replacement, prevents the metabolic deficits of adrenalectomy. J. Neuroendocrinol., $12,461-470$. 
Berridge, K.C. ( 2009 ) 'Liking' and 'wanting' food rewards: brain substrates and roles in eating disorders. Physiol. Behav., 97, $537-550$.

Berry, J.N., Saunders, M.A., Sharrett-Field, L.J., Reynolds, A.R., Bardo, M.T., Pauly, J.R. \& Prendergast, M.A. ( 2016 ) Corticosterone enhances N-methyl-D-aspartate receptor signaling to promote isolated ventral tegmental area activity in a reconstituted mesolimbic dopamine pathway. Brain Res. Bull., 120, 159 165.

$\underline{6}$ Bhatnagar, S., Bell, M.E., Liang, J., Soriano, L., Nagy, T.R. \& Dallman, M.F. ( 2000 ) Corticosterone facilitates saccharin intake in adrenalectomized rats: does corticosterone increase stimulus salience? J. Neuroendocrinol., 12, $453-460$.

7 Bocklisch, C., Pascoli, V., Wong, J.C., House, D.R., Yvon, C., de Roo, M., Tan, K.R. \& Luscher, C. ( 2013 ) Cocaine disinhibits dopamine neurons by potentiation of GABA transmission in the ventral tegmental area. Science, 341, $1521-1525$.

$\underline{8}$ Cheer, J.F., Wassum, K.M., Sombers, L.A., Heien, M.L., Ariansen, J.L., Aragona, B.J., Phillips, P.E. \& Wightman, R.M. ( 2007 ) Phasic dopamine release evoked by abused substances requires cannabinoid receptor activation. J. Neurosci., 27, $791-795$.

$\underline{9}$ Chergui, K., Charlety, P.J., Akaoka, H., Saunier, C.F., Brunet, J.L., Buda, M., Svensson, T.H. \& Chouvet, G. ( 1993 ) Tonic activation of NMDA receptors causes spontaneous burst discharge of rat midbrain dopamine neurons in vivo. Eur. J. Neurosci., 5, $137-144$.

10 Cho, K. \& Little, H.J. ( 1999 ) Effects of corticosterone on excitatory amino acid responses in dopaminesensitive neurons in the ventral tegmental area. Neuroscience, 88, 837-845.

$\underline{11}$ Cone, J.J., Fortin, S.M., McHenry, J.A., Stuber, G.D., McCutcheon, J.E. \& Roitman, M.F. ( 2016 ) Physiological state gates acquisition and expression of mesolimbic reward prediction signals. Proc. Natl. Acad. Sci. USA, 113, $1943-1948$.

12 Cragg, S.J. \& Rice, M.E. ( 2004 ) DAncing past the DAT at a DA synapse. Trends Neurosci., 27, $270-277$.

13 Dallman, M.F. ( 2010 ) Stress-induced obesity and the emotional nervous system. TEM, 21, 159- 165.

14 Dallman, M.F., Pecoraro, N.C. \& la Fleur, S.E. ( 2005 ) Chronic stress and comfort foods: self-medication and abdominal obesity. Brain Behav. Immun., 19, $275-280$.

15 Deroche, V., Marinelli, M., Le Moal, M. \& Piazza, P.V. ( 1997 ) Glucocorticoids and behavioral effects of psychostimulants. II: cocaine intravenous self-administration and reinstatement depend on glucocorticoid levels. J. Pharmacol. Exp. Ther., 281, $1401-1407$.

16 Erb, S., Shaham, Y. \& Stewart, J. ( 1998 ) The role of corticotropin-releasing factor and corticosterone in stress- and cocaine-induced relapse to cocaine seeking in rats. J. Neurosci., 18, $5529-5536$.

17 Gasser, P.J., Lowry, C.A. \& Orchinik, M. ( 2006 ) Corticosterone-sensitive monoamine transport in the rat dorsomedial hypothalamus: potential role for organic cation transporter 3 in stress-induced modulation of monoaminergic neurotransmission. J. Neurosci., 26, $8758-8766$.

18 Goeders, N.E. \& Guerin, G.F. ( 1994 ) Non-contingent electric footshock facilitates the acquisition of intravenous cocaine self-administration in rats. Psychopharmacology, 114, $63-70$.

19 Goeders, N.E. \& Guerin, G.F. ( 1996a ) Effects of surgical and pharmacological adrenalectomy on the initiation and maintenance of intravenous cocaine self-administration in rats. Brain Res., 722, $145-152$.

$\underline{20}$ Goeders, N.E. \& Guerin, G.F. ( 1996b ) Role of corticosterone in intravenous cocaine self-administration in rats. Neuroendocrinology, 64, $337-348$.

$\underline{21}$ Graf, E.N., Wheeler, R.A., Baker, D.A., Ebben, A.L., Hill, J.E., McReynolds, J.R., Robble, M.A., Vranjkovic, O. et al. ( 2013 ) Corticosterone acts in the nucleus accumbens to enhance dopamine signaling and potentiate reinstatement of cocaine seeking. J. Neurosci., 33, $11800-11810$.

22 Heien, M.L., Johnson, M.A. \& Wightman, R.M. ( 2004 ) Resolving neurotransmitters detected by fast-scan cyclic voltammetry. Anal. Chem., 76, $5697-5704$. 
23 Heien, M.L., Khan, A.S., Ariansen, J.L., Cheer, J.F., Phillips, P.E., Wassum, K.M. \& Wightman, R.M. ( 2005 ) Real-time measurement of dopamine fluctuations after cocaine in the brain of behaving rats. Proc. Natl. Acad. Sci. USA, 102, 10023 - 10028.

24 Hill, J.E., Makky, K., Shrestha, L., Hillard, C.J. \& Gasser, P.J. ( 2011 ) Natural and synthetic corticosteroids inhibit uptake 2-mediated transport in CNS neurons. Physiol. Behav., 104, $306-311$.

25 Howell, L.A., Harris, R.B., Clarke, C., Youngblood, B.D., Ryan, D.H. \& Gilbertson, T.A. ( 1999 ) The effects of restraint stress on intake of preferred and nonpreferred solutions in rodents. Physiol. Behav., 65, 697704.

$\underline{26}$ Hyman, S.E., Malenka, R.C. \& Nestler, E.J. ( 2006 ) Neural mechanisms of addiction: the role of reward-related learning and memory. Annu. Rev. Neurosci., 29, 565 - 598.

27 Iversen, L.L. \& Salt, P.J. ( 1970 ) Inhibition of catecholamine Uptake-2 by steroids in the isolated rat heart. Br. J. Pharmacol., 40, $528-530$.

$\underline{28}$ Lee, B., Tiefenbacher, S., Platt, D.M. \& Spealman, R.D. ( 2003 ) Role of the hypothalamic-pituitary-adrenal axis in reinstatement of cocaine-seeking behavior in squirrel monkeys. Psychopharmacology, 168, $177-183$.

$\underline{29}$ Liang, N.C., Smith, M.E. \& Moran, T.H. ( 2013 ) Palatable food avoidance and acceptance learning with different stressors in female rats. Neuroscience, 235, $149-158$.

30 Mantsch, J.R. \& Goeders, N.E. ( 1998 ) Generalization of a restraint-induced discriminative stimulus to cocaine in rats. Psychopharmacology, 135, $423-426$.

31 Mantsch, J.R. \& Goeders, N.E. ( 1999 ) Ketoconazole blocks the stress-induced reinstatement of cocaineseeking behavior in rats: relationship to the discriminative stimulus effects of cocaine. Psychopharmacology, 142, $399-407$.

32 Mantsch, J.R. \& Katz, E.S. ( 2007 ) Elevation of glucocorticoids is necessary but not sufficient for the escalation of cocaine self-administration by chronic electric footshock stress in rats. Neuropsychopharmacol, 32, $367-376$.

33 Mantsch, J.R., Vranjkovic, O., Twining, R.C., Gasser, P.J., McReynolds, J.R. \& Blacktop, J.M. ( 2014 ) Neurobiological mechanisms that contribute to stress-related cocaine use. Neuropharmacology, 76 ( Pt B ), $383-394$.

34 Marinelli, M., Rouge-Pont, F., De Jesus-Oliveira, C., Le Moal, M. \& Piazza, P.V. ( 1997a ) Acute blockade of corticosterone secretion decreases the psychomotor stimulant effects of cocaine. Neuropsychopharmacol, 16, $156-161$.

$\underline{35}$ Marinelli, M., Rouge-Pont, F., Deroche, V., Barrot, M., De Jesus-Oliveira, C., Le Moal, M. \& Piazza, P.V. ( 1997b ) Glucocorticoids and behavioral effects of psychostimulants. I: locomotor response to cocaine depends on basal levels of glucocorticoids. J. Pharmacol. Exp. Ther., 281, 1392- 1400.

36 McCutcheon, J.E., Beeler, J.A. \& Roitman, M.F. ( 2012 ) Sucrose-predictive cues evoke greater phasic dopamine release than saccharin-predictive cues. Synapse, 66, $346-351$.

37 McReynolds, J.R., Taylor, A., Vranjkovic, O., Ambrosius, T., Derricks, O., Nino, B., Kurtoglu, B., Wheeler, R.A. et al. ( 2017 ) Corticosterone potentiation of cocaine-induced reinstatement of conditioned place preference in mice is mediated by blockade of the organic cation transporter 3 . Neuropsychopharmacology, 42, $757-765$.

38 Pecoraro, N., Reyes, F., Gomez, F., Bhargava, A. \& Dallman, M.F. ( 2004 ) Chronic stress promotes palatable feeding, which reduces signs of stress: feedforward and feedback effects of chronic stress. Endocrinology, 145, $3754-3762$.

39 Piazza, P.V., Rouge-Pont, F., Deroche, V., Maccari, S., Simon, H. \& Le Moal, M. ( 1996 ) Glucocorticoids have state-dependent stimulant effects on the mesencephalic dopaminergic transmission. Proc. Natl. Acad. Sci. USA, 93, $8716-8720$.

40 Plaznik, A., Stefanski, R. \& Kostowski, W. ( 1989 ) Restraint stress-induced changes in saccharin preference: the effect of antidepressive treatment and diazepam. Pharmacol. Biochem. Behav., 33, 755 - 759. 
$\underline{41}$ Reynolds, S.M. \& Berridge, K.C. ( 2008 ) Emotional environments retune the valence of appetitive versus fearful functions in nucleus accumbens. Nat. Neurosci., 11, $423-425$.

$\underline{42}$ Roitman, M.F., Wheeler, R.A., Wightman, R.M. \& Carelli, R.M. ( 2008 ) Real-time chemical responses in the nucleus accumbens differentiate rewarding and aversive stimuli. Nat. Neurosci., 11, $1376-1377$.

43 Rouge-Pont, F., Marinelli, M., Le Moal, M., Simon, H. \& Piazza, P.V. ( 1995 ) Stress-induced sensitization and glucocorticoids. II. Sensitization of the increase in extracellular dopamine induced by cocaine depends on stress-induced corticosterone secretion. J. Neurosci., 15, 7189- 7195.

44 Rowland, N.E. \& Antelman, S.M. ( 1976 ) Stress-induced hyperphagia and obesity in rats: a possible model for understanding human obesity. Science, 191, 310-312.

45 Silva, M.T. ( 1977 ) Saccharin aversion in the rat following adrenalectomy. Physiol. Behav., 19, 239 - 244.

46 Sombers, L.A., Beyene, M., Carelli, R.M. \& Wightman, R.M. ( 2009 ) Synaptic overflow of dopamine in the nucleus accumbens arises from neuronal activity in the ventral tegmental area. J. Neurosci., 29, $1735-$ 1742.

47 Sominsky, L. \& Spencer, S.J. ( 2014 ) Eating behavior and stress: a pathway to obesity. Front. Psychol., 5, 434. 48 Spencer, R.L. \& Deak, T. ( 2017 ) A users guide to HPA axis research. Physiol. Behav., 178, $43-65$.

49 Stuber, G.D., Wightman, R.M. \& Carelli, R.M. ( 2005 ) Extinction of cocaine self-administration reveals functionally and temporally distinct dopaminergic signals in the nucleus accumbens. Neuron, 46, $661-$ 669.

50 Tataranni, P.A., Larson, D.E., Snitker, S., Young, J.B., Flatt, J.P. \& Ravussin, E. ( 1996 ) Effects of glucocorticoids on energy metabolism and food intake in humans. Am. J. Physiol., 271, E317 - E325.

51 Twining, R.C., Wheeler, D.S., Ebben, A.L., Jacobsen, A.J., Robble, M.A., Mantsch, J.R. \& Wheeler, R.A. ( 2015 ) Aversive stimuli drive drug seeking in a state of low dopamine tone. Biol. Psychiat., 77, 895 - 902.

52 Ulrich-Lai, Y.M., Ostrander, M.M. \& Herman, J.P. ( 2011 ) HPA axis dampening by limited sucrose intake: reward frequency vs. caloric consumption. Physiol. Behav., 103, 104 - 110.

$\underline{53}$ Vander Weele, C.M., Porter-Stransky, K.A., Mabrouk, O.S., Lovic, V., Singer, B.F., Kennedy, R.T. \& Aragona, B.J. ( 2014 ) Rapid dopamine transmission within the nucleus accumbens: dramatic difference between morphine and oxycodone delivery. Eur. J. Neurosci., 40, 3041 - 3054.

54 Volkow, N.D., Wang, G.J., Fowler, J.S. \& Telang, F. ( 2008 ) Overlapping neuronal circuits in addiction and obesity: evidence of systems pathology. Phil. Trans. R. Soc. B Biol. Sci., 363, $3191-3200$.

$\underline{55}$ Wheeler, R.A., Twining, R.C., Jones, J.L., Slater, J.M., Grigson, P.S. \& Carelli, R.M. ( 2008 ) Behavioral and electrophysiological indices of negative affect predict cocaine self-administration. Neuron, 57, 774 785.

$\underline{56}$ Wheeler, R.A., Aragona, B.J., Fuhrmann, K.A., Jones, J.L., Day, J.J., Cacciapaglia, F., Wightman, R.M. \& Carelli, R.M. ( 2011 ) Cocaine cues drive opposing context-dependent shifts in reward processing and emotional state. Biol. Psychiat., 69, $1067-1074$.

57 Wheeler, D.S., Robble, M.A., Hebron, E.M., Dupont, M.J., Ebben, A.L. \& Wheeler, R.A. ( 2015 ) Drug predictive cues activate aversion-sensitive striatal neurons that encode drug seeking. J. Neurosci., 35, $7215-7225$.

58 Wightman, R.M., Amatore, C., Engstrom, R.C., Hale, P.D., Kristensen, E.W., Kuhr, W.G. \& May, L.J. ( 1988 ) Real-time characterization of dopamine overflow and uptake in the rat striatum. Neuroscience, 25, 513 $-523$.

$\underline{59}$ Wightman, R.M., Heien, M.L., Wassum, K.M., Sombers, L.A., Aragona, B.J., Khan, A.S., Ariansen, J.L., Cheer, J.F. et al. ( 2007 ) Dopamine release is heterogeneous within microenvironments of the rat nucleus accumbens. Eur. J. Neurosci., 26, 2046 - 2054.

60 Wultsch, T., Grimberg, G., Schmitt, A., Painsipp, E., Wetzstein, H., Breitenkamp, A.F., Grundemann, D., Schomig, E. et al. ( 2009 ) Decreased anxiety in mice lacking the organic cation transporter 3. J. Neural. Transm. (Vienna), 116, $689-697$. 
Graph: Average colorplots depict the dopamine response to corticosterone and cocaine. Blue arrows show the treatments during the three experimental phases. Colorplots depict cyclic voltammetric data during an average of the 30-s bins during each experimental phase for representative rats from each group. The ordinate is the applied voltage, and the abscissa is time. Changes in current detected by the carbon fiber electrode are indicated in color. [Colour figure can be viewed at wileyonlinelibrary.com ].

Graph: Corticosterone augments the response to cocaine in the NA c core and shell. (A) Mean time-averaged DA concentrations of corticosterone-injected subjects in each the recording subregion (shell or core). Open circles show means for individual subjects. There was no significant difference between the two subregions ( $P$ $S>0.40$ ). (B) Mean time-averaged DA concentrations during the different phases of the experiment for vehicle and corticosterone (Cort) injected subjects. Asterisk indicate significant differences ( P s <.05). DA concentrations were elevated after corticosterone $(2 \mathrm{mg} / \mathrm{kg}$, i.p.) administration ( $P<0.007)$, and further elevated after an injection of low-dose cocaine $(2.5 \mathrm{mg} / \mathrm{kg}$ i.p.; $\mathrm{P}<0.001)$. (C) Electrode placements for vehicle- (gray) and corticosterone (black)-treated subjects in the core (Xs) and shell (Os) of the NA c. [Colour figure can be viewed at wileyonlinelibrary.com ].

Graph: Corticosterone selectively affects uptake-sensitive characteristics of DA transients. (A) The colorplot (left) depicts DA transients in one subject. The white arrows identify six transients that occurred over $20 \mathrm{~s}$. The line graph (right) isolates the current at DA 's oxidation potential and depicts the uptake-sensitive measures of spontaneous DA transients (amplitude and half-width). (B) Means showing the average transient amplitude ( $\mathrm{nM}$ ) during the different phases of the experiment for vehicle- and corticosterone (Cort)-injected subjects. Open circles show data for individual subjects. Asterisk indicate significant differences ( $P$ s <.05). Transient amplitude increased after corticosterone administration ( $P<0.007$ ), and increased further after cocaine administration ( $P<0.005)$. (C) Average transient half-width (ms). Half-width increased after corticosterone administration ( $P<0.001)$, and increased further after cocaine administration $(P<0.001)$. Cocaine did have an effect on halfwidth after vehicle administration ( $P<0.03$ ), but the effect of cocaine was larger when administered after corticosterone ( $P<0.001$ ). (D) Average transient frequency (counts/min). Transient frequency was unaffected by vehicle, corticosterone, and cocaine administration, indicating that corticosterone and cocaine selectively affected DA clearance ( P s > 0.07). [Colour figure can be viewed at wileyonlinelibrary.com ].

Graph: Corticosterone does not affect the DA response to an appetitive taste. (A) The timing of events in the saccharin experiment. Thirty 15-s saccharin infusions (red tick-marks) were administered during the pre- and post-corticosterone saccharin phases. (B) An average colorplot for a representative rat showing the DA response to the saccharin infusions (horizontal red bar). (C) Means ( \pm SEM ) of the average change in DA concentration during saccharin infusion before (black) and after (blue) corticosterone administration. (D) Means of the average change in DA concentration during the baseline and saccharin epochs. Open circles show means for individual subjects. Saccharin increased DA concentration $(P<0.02$ ), but this effect was unaltered by corticosterone administration ( $\mathrm{P} \mathrm{s}>0.77$ ). (E) Electrode placements. [Colour figure can be viewed at wileyonlinelibrary.com ].

Graph

By Daniel S. Wheeler; Amanda L. Ebben; Beliz Kurtoglu; Marissa E. Lovell; Austin T. Bohn; Isabella A. Jasek; David A. Baker; John R. Mantsch; Paul J. Gasser and Robert A. Wheeler 
Copyright of European Journal of Neuroscience is the property of Wiley-Blackwell and its content may not be copied or emailed to multiple sites or posted to a listserv without the copyright holder's express written permission. However, users may print, download, or email articles for individual use.

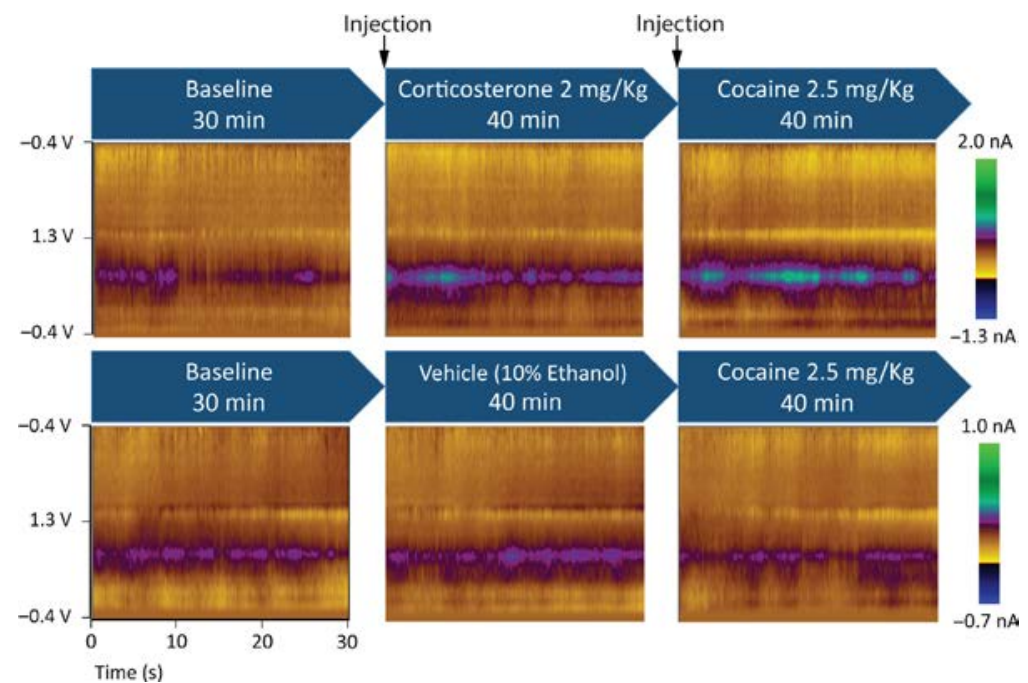

Fig. 1. Average colorplots depict the dopamine response to corticosterone and cocaine. Blue arrows show the treatments during the three experimental phases. Colorplots depict cyclic voltammetric data during an average of the 30-s bins during each experimental phase for representative rats from each group. The ordinate is the applied voltage, and the abscissa is time. Changes in current detected by the carbon fiber electrode are indicated in color. [Colour figure can be viewed at wileyonlinelibrary.com].
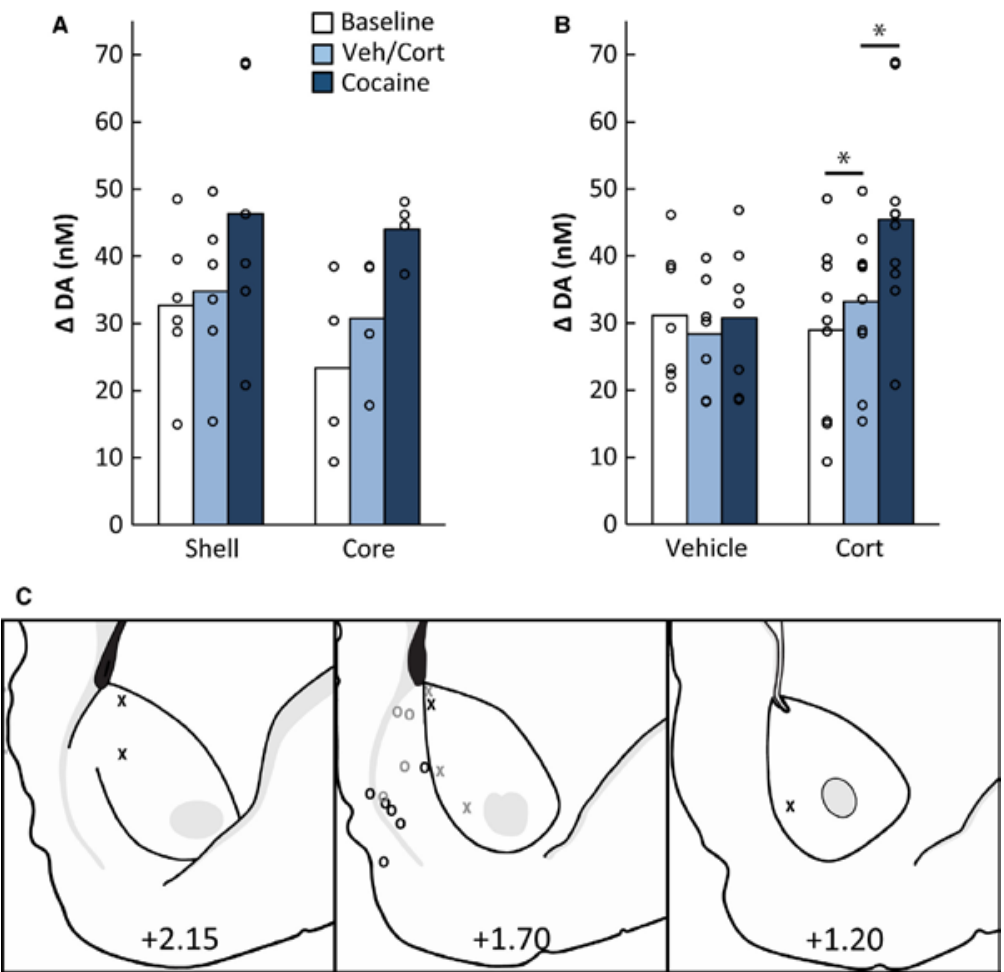

Fig. 2. Corticosterone augments the response to cocaine in the NAc core and shell. (A) Mean time-averaged DA concentrations of corticosterone-injected subjects in each the recording subregion (shell or core). Open circles show means for individual subjects. There was no significant difference between the two subregions (Ps $>0.40$ ). (B) Mean time-averaged DA concentrations during the different phases of the experiment for vehicle and corticosterone (Cort) injected subjects. Asterisk indicate significant differences (Ps < .05). DA concentrations 
were elevated after corticosterone $(2 \mathrm{mg} / \mathrm{kg}$, i.p.) administration $(P<0.007)$, and further elevated after an injection of low-dose cocaine $(2.5 \mathrm{mg} / \mathrm{kg}$ i.p.; $\mathrm{P}<0.001)$. (C) Electrode placements for vehicle- (gray) and corticosterone (black)- treated subjects in the core (Xs) and shell (Os) of the NAc. [Colour figure can be viewed at wileyonlinelibrary.com].

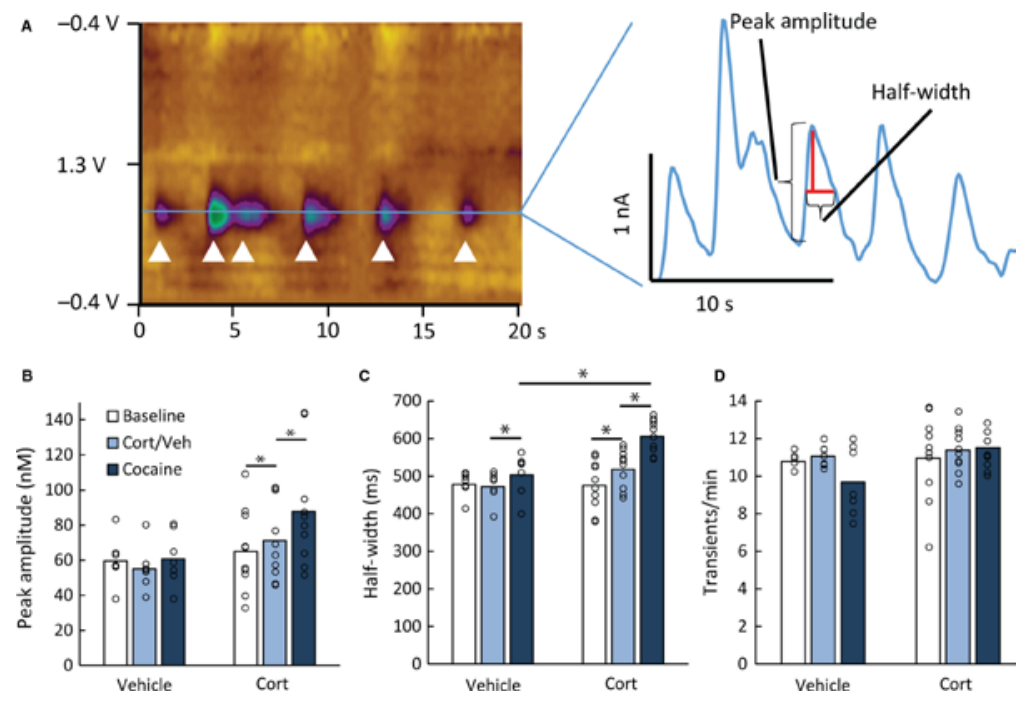

Fig. 3. Corticosterone selectively affects uptake-sensitive characteristics of DA transients. (A) The colorplot (left) depicts DA transients in one subject. The white arrows identify six transients that occurred over $20 \mathrm{~s}$. The line graph (right) isolates the current at DA's oxidation potential and depicts the uptake-sensitive measures of spontaneous DA transients (amplitude and half-width). (B) Means showing the average transient amplitude (nM) during the different phases of the experiment for vehicle- and corticosterone (Cort)-injected subjects. Open circles show data for individual subjects. Asterisk indicate significant differences (Ps <.05). Transient amplitude increased after corticosterone administration $(P<0.007)$, and increased further after cocaine administration $(P<$ 0.005). (C) Average transient half-width (ms). Half-width increased after corticosterone administration $(P<$ 0.001), and increased further after cocaine administration $(P<0.001)$. Cocaine did have an effect on half-width after vehicle administration $(P<0.03)$, but the effect of cocaine was larger when administered after corticosterone $(P<0.001)$. (D) Average transient frequency (counts/min). Transient frequency was unaffected by vehicle, corticosterone, and cocaine administration, indicating that corticosterone and cocaine selectively affected DA clearance (Ps >0.07). [Colour figure can be viewed at wileyonlinelibrary.com]. 


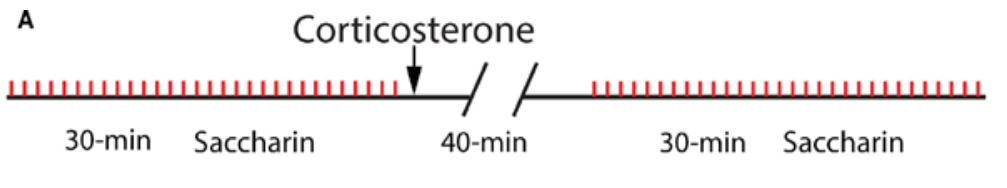

B

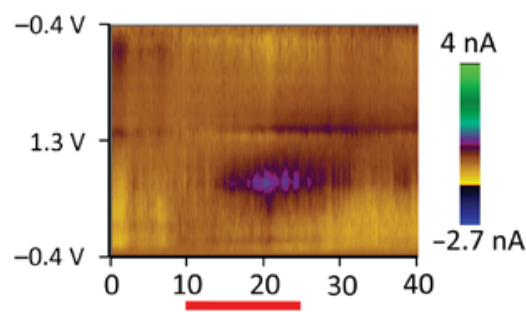

D 50 Time (s)

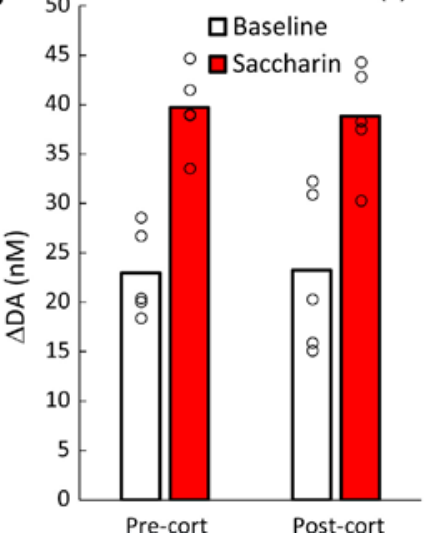

C

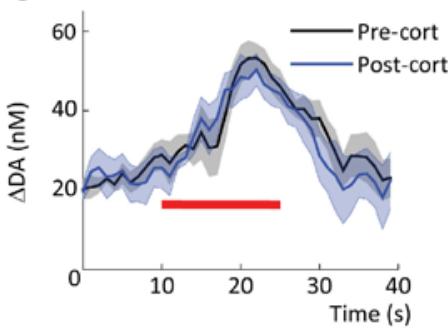

E

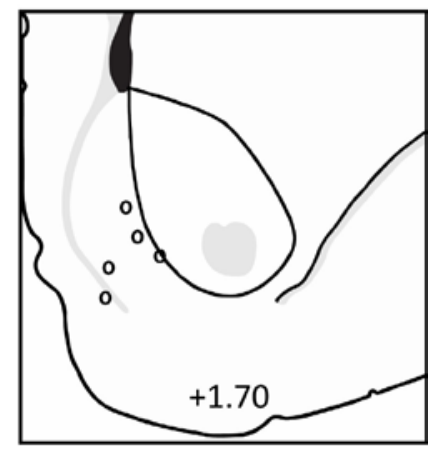

Fig. 4. Corticosterone does not affect the DA response to an appetitive taste. (A) The timing of events in the saccharin experiment. Thirty 15-s saccharin infusions (red tick-marks) were administered during the pre- and post-corticosterone saccharin phases. (B) An average colorplot for a representative rat showing the DA response to the saccharin infusions (horizontal red bar). (C) Means (? SEM) of the average change in DA concentration during saccharin infusion before (black) and after (blue) corticosterone administration. (D) Means of the average change in DA concentration during the baseline and saccharin epochs. Open circles show means for individual subjects. Saccharin increased DA concentration $(P<0.02)$, but this effect was unaltered by corticosterone administration (Ps > 0.77). (E) Electrode placements. [Colour figure can be viewed at wileyonlinelibrary.com]. 